\title{
sciendo
}

Transport and Telecommunication, 2021, volume 22, no. 2, 230-243

Transport and Telecommunication Institute, Lomonosova 1, Riga, LV-1019, Latvia

DOI 10.2478/ttj-2021-0018

\section{ROAD DESIGN CRITERIA AND CAPACITY ESTIMATION BASED ON AUTONOMOUS VEHICLES PERFORMANCES. FIRST RESULTS FROM THE EUROPEAN C-ROADS PLATFORM AND A22 MOTORWAY}

\author{
Marco Guerrieri ${ }^{1}$, Raffaele Mauro ${ }^{1}$, Andrea Pompigna ${ }^{1}$, Natalia Isaenko ${ }^{2}$ \\ ${ }^{I}$ DICAM, University of Trento \\ Via Mesiano, 77, Trento, Italy \\ marco.guerrieri@unitn.it; raffaele.mauro@unitn.it; andrea.pompigna3@gmail.com \\ ${ }^{2}$ DICEA, University La Sapienza of Rome \\ Via Eudossiana, 18, Rome, Italy \\ natalia.isaenko@uniroma1.it
}

\begin{abstract}
Several European road operators and authorities joined the C-Roads Platform with the aim of harmonising the deployment activities of cooperative intelligent transport systems (C-ITS). C-ITS research is preliminary to future automated-driving vehicles. The current conventional highways were designed on traditional criteria and models specifically developed for traffic flows of manually guided vehicles. Thus, this article describes some new criteria for designing and monitoring road infrastructures on the basis of performance features of autonomous (or self-driving) vehicles.

The new criteria have been adopted to perform an accurate conformity control of the A22 Brenner motorway, included in the C-Roads Platform, and also to ascertain whether in future it may be travelled by automated vehicles in safety conditions. Always in accordance with the technical and scientific insights required by the C-Roads Platform, a traffic model has been implemented to estimate how the A22 capacity increases compared to current values, by taking various percentages of automated or manual vehicles into consideration. The results given by theoretical models indicate that the highway will be able to be travelled by automated vehicles in safety conditions. On the other hand, the lane capacity is due to increase up to 2.5 times more than the current capacities, experimentally determined through traffic data collected from 4 highway sections by means of Drake's flow model.
\end{abstract}

Keywords: smart road, automated vehicles, design and review criteria, capacity estimation

\section{Introduction}

Planners and engineers usually must estimate operational improvement strategies to eliminate, mitigate, or avoid traffic congestion and phenomenal safety issues in highways and road intersections (Guerrieri et al., 2015; Tollazzi et al., 2016). These strategies are based on traffic counts and infrastructure performance monitoring.

Highway traffic control systems and intelligent transportation systems (ITS) are commonly used around the world, especially in USA and Europe, with the primary aim of countering recurrent congestion (i.e. when demand increases beyond the available capacity) and non-recurrent congestion (i.e. temporary decrease in capacity while the demand remains unchanged) (Gordon, 2010).

In addition, ITS are involved in the following areas (Ioannou, 1997): Advanced Traffic Management Systems (ATMS), Advanced Traveller Information Systems (ATIS), Advanced Vehicle Control Systems (AVCS), Commercial Vehicle Operations (CVO), Advanced Public Transportation Systems (APTS). The main traditional highway traffic control systems implementing ITS are: truck policies (TP), ramp metering (RM), high occupancy vehicle (HOV) lanes, real-time variable speed limits (VSLs), reversible lanes (RL) and hard-shoulder running (HSR) (Elefteriadou, 2014; Papageorgiou, 2014). The cooperative intelligent transportation system (C-ITS) is an emerging technology based on the communication and cooperation between vehicles, as well as between vehicles and physical infrastructures (urban roads, highways etc.). Along with new driverless vehicles, the digital cooperation between vehicles and infrastructures will promote a potentially significant improvement in road safety, capacity, sustainability and driving comfort. C-ITS enables the bi-directional and real-time data exchange of road safety and traffic efficiency related information between vehicles and traffic management centres. In the very near future, thanks to digital connectivity, vehicles will interact directly with each other and with physical infrastructures (urban roads, highways, etc.). By means of the C-Roads Platform, several road operators and authorities join together to harmonise the deployment activities of cooperative intelligent transport systems (C-ITS) in the European countries (C-Roads Platform). The main objective is the deployment of interoperable cross-border C-ITS services for road users, especially the so-called "Day 1 - C-ITS service" (Table 1). 
Table 1. Day 1Table C-ITS service list and Day 1.5 C-ITS service list

\begin{tabular}{|l|l|}
\hline \multicolumn{1}{|c|}{ Day 1 C-ITS service list } & Day 1.5 C-ITS service list \\
\hline Hazardous location notifications: & - Information on fuelling \& charging stations for alternative \\
- Slow or stationary vehicle(s) \& traffic ahead warning & - Vulnerable road user protection \\
- Road works warning & - On street parking management \& information \\
- Weather conditions & - Off street parking information \\
- Emergency brake light & - Park \& ride information \\
- Emergency vehicle approaching & - Connected \& cooperative navigation into and out of the city \\
- Other hazards & (first and last mile, parking, route advice, coordinated \\
Signage applications: & traffic lights) \\
- In-vehicle signage & Traffic information \& smart routing \\
- In-vehicle speed limits & \\
- Signal violation / intersection safety & \\
- Traffic signal priority request by designated vehicles & \\
- Green light optimal speed advisory (GLOSA) & \\
- Probe vehicle data & \\
- Shockwave damping (falling under European & \\
Telecommunication Standards Institute - ETSI category & \\
'local hazard warning'). & \\
\hline
\end{tabular}

The core C-Roads Platform members (Figure 1 (a)) are: Austria, Belgium/Flanders, Belgium/Wallonia, Czech Republic, Denmark, Finland, France, Germany, Hungary, Italy, the Netherlands, Norway, Portugal, Slovenia, Spain, Sweden and the United Kingdom. The core members are involved with their own C-ITS pilot deployments, either in place or in preparation. In addition, a lot of associated members follow the C-Roads Platform as well as the pilot deployments of C-ITS services closely.

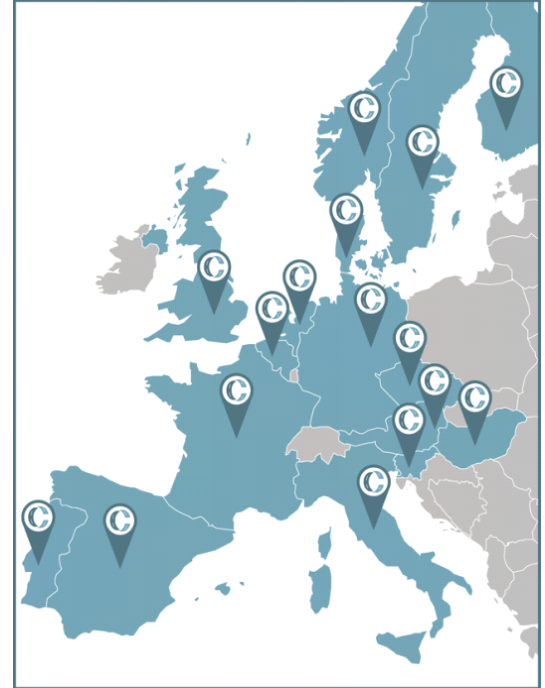

(a)

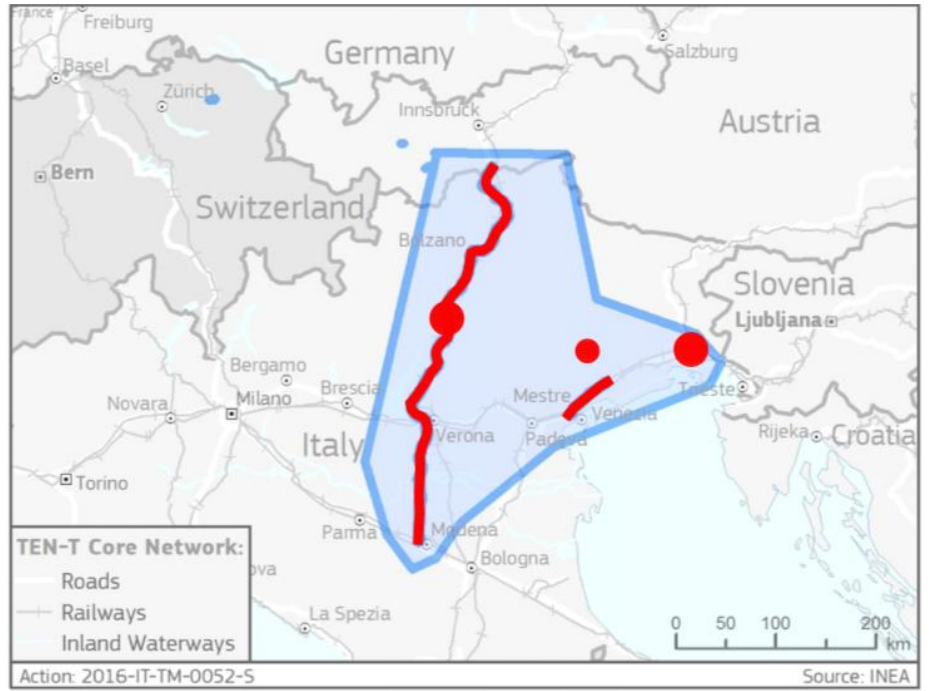

(b)

Figure 1. (a) Core C-Roads Platform members, (b) C-Roads projects in Italy

The Italian motorway operators involved in the C-Roads Platform with their corresponding infrastructure are (Figure 1(b)): the A22 S.p.A. (A22 motorway, $313 \mathrm{~km}$ ); the "Autovie Venete motorways" (A4, A28 motorways $19 \mathrm{~km}$ and $5 \mathrm{~km}$, respectively) and the CAV "Consorzio Autostrade Venete" (A57 motorway, $7 \mathrm{~km}$ ). In Italy the key objectives of the C-Roads project are the implementation and testing, in real traffic conditions, of cooperative systems based on Vehicle-to-Everything (V2X) technologies, for automated driving applications, such as:

- truck platooning;

- highway chauffeur for passenger cars;

- combined scenarios of trucks and passenger cars.

That requires upgrading motorways as well as integrating Vehicle-to-Infrastructure (V2I) C-ITS service and Vehicle-to-Vehicle (V2V) information with vehicle control strategies. The expected potential benefits are in terms of safety (risk reduction related to cooperative/automated technology in truck and passenger cars scenarios), capacity and level of service (due to platooning and highway chauffeur technologies) and energy efficiency (reduction in fuel consumption and pollutant emissions).

The Day 1 C-ITS services (see Table 1 and Figure 2) have been taken into account in the projects. Present C-ITS deployments are founded on the communication technologies IEEE802.11p/ETSI ITS-G5 (in short, ITS-G5) as well as on $3 \mathrm{G}$ and $4 \mathrm{G}$ cellular standards. 


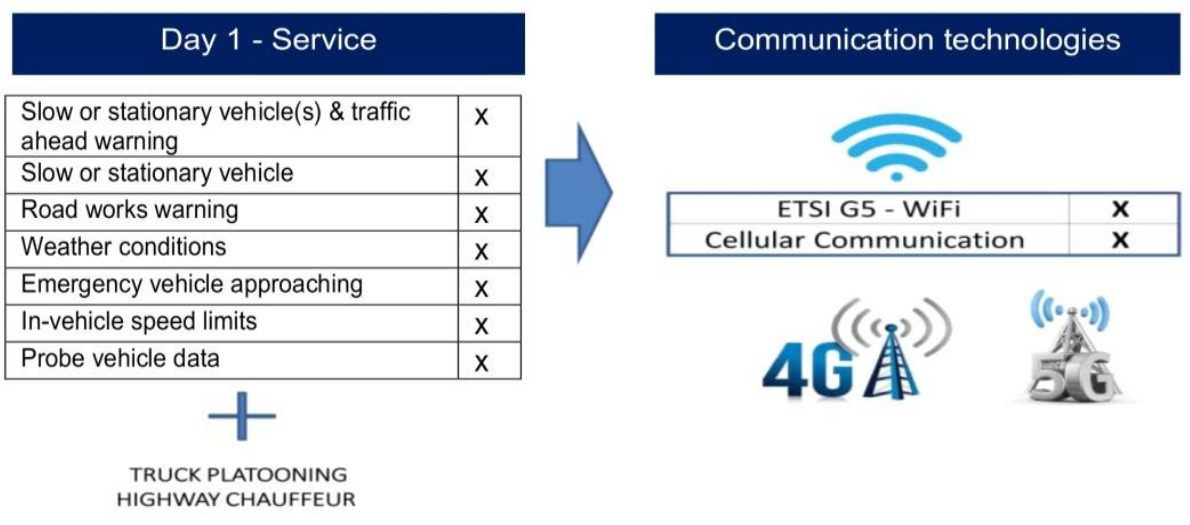

Figure 2. C-ITS services implemented in the A22 Motorway
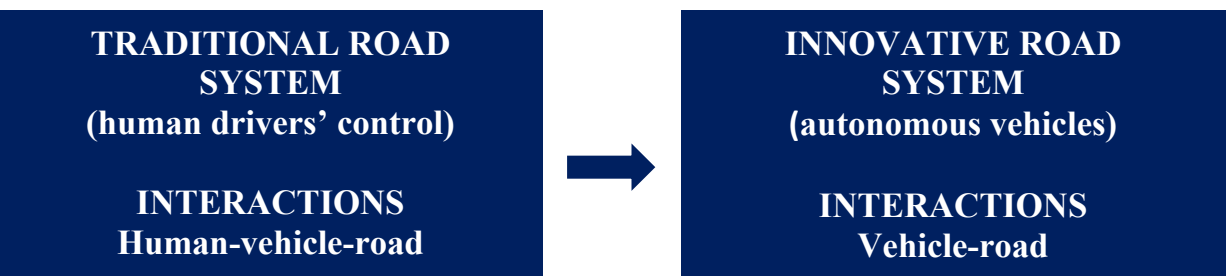

Figure 3. Ideal transition from a traditional to an innovative road system

Table 2. Comparison between manual and automated driving systems

\begin{tabular}{|c|c|}
\hline Human drivers' control & Autonomous vehicles \\
\hline Perception & LIDAR ${ }^{*}$, Radar, Video cameras, GPS \\
\hline Reaction & Pre-programmed algorithms, artificial intelligence \\
\hline Experience and competence & Not necessary \\
\hline
\end{tabular}

*Light Detection and Ranging or Laser Imaging Detection and Ranging

Recent innovation in vehicle automation fosters in-depth analysis of the design criteria for road infrastructures. As a matter of fact, design criteria are to be modified since the human factors are going to be less significant in driving processes (Berktaş and Tanyel). Thus, there will be an ideal transition from the current transport system based on the interaction among human-vehicle-road components to a system interacting between only two components, vehicle-road (and vehicle-vehicle) which is simplified in some ways, but more complex in others (Figure 3 and Table 2). Automated vehicles are still at the experimental stage. But in the medium/long term they are expected to replace manual driving vehicles gradually and completely. Thus the conventional road patterns are supposed to evolve over time into the following scenarios:

- Scenario 1 (current): traffic flow composed only of traditionally driven vehicles;

- Scenario 2 (medium-term): mixed traffic flow consisting of both manual and automated driving vehicles;

- Scenario 3 (long-term): traffic flow composed only of automated driving vehicles.

Consequently, road geometry should have planimetric and altimetric features specifically examined for automated driving vehicles, apart from the technological elements for information exchange between infrastructure and vehicle as described above.

At present, neither technical standards nor guidelines on design criteria for such new generation infrastructures have been provided by competent bodies and specialised techno-scientific associations.

Thus, this research aims to formalise some design criteria for new generation of infrastructures which are based on the performance characteristics of automated driving vehicles. It focuses on the A22 Italian motorway and hence design criteria laid down by the current Italian technical regulations (D.M. n. 6792. 5/11/2001) were globally revised.

These new theoretical criteria have been adopted for assessing the A22 Brenner motorway geometrically and determine whether it can be used by automated vehicles in safety conditions. In addition, 
among the experiments set up in the C-Roads Platform, a new traffic model was implemented to estimate the expected increase in infrastructure capacity, compared to the present values (experimentally determined through the Drake model), in function of the traffic flow composition (that is, of different percentages of manual and automated driving vehicles).

\section{Design criteria for road infrastructures used by automated driving vehicles}

Below are the criteria for the highway geometric alignment to be dimensioned in infrastructures dedicated to automated driving vehicles. They were established by particularising those traditionally employed in highway engineering in function of the so-far known performances of automated driving vehicles. The following three modes of infrastructure use have been considered in the research:

- Traffic flow composed only of manual driving (M.D.) vehicles, or 100\% M.D.;

- Mixed traffic flow consisting of manual driving (M.D.) and automated driving (A.D.) vehicles;

- Traffic flow composed only of automated driving (A.D.) vehicles, or 100\% A.D.

Clearly, the infrastructures which at the same time can be used by manual and automated driving vehicles must meet the same safety standards as traditional infrastructures (100\% M.D.). In other words, the geometrical alignment of the infrastructures specified at point 2 in the list must keep the same characteristics as traditional roads. As said, the design and review criteria depend on the user behaviours (for manual driving vehicles) and on the automated driving systems (for driverless vehicles).

\subsection{Stopping sight distance - SSD for traditional and automated vehicles}

It is well known that the traditional road design criteria are based on human factors. Consequently, a pivotal role is played by the perception-reaction time $(P R T)$. According to AASHTO, in case of unexpected situations some drivers take PRT up to 2.7 seconds (NCHRP, Report 600). Experiments conducted in highways have shown that the 85 th percentile of the perception-reaction time distribution corresponds to 1.9 seconds (Sens et al., 1989). In the urban context, the perception-reaction time assumes values up to $2.5 \mathrm{sec}$ (Lerner, 1993). In Italy the present technical regulations (D.M. n. 6792. 5/11/2001) provides the following expression:

$P R T=(2.8-0.01 \mathrm{~V})$,

$V$ being the vehicle speed in $\mathrm{km} / \mathrm{h}$.

The same regulations specify that in such particular situations as, for instance, the 'complex' intersections, the value calculated with (1) must be increased by a second in a suburban area and up to 3 seconds in an urban area. For automated vehicles, reaction delay $(P R T)$ value is the sum of sensing, computing, communication and actuating delays. Typical PRT values are (Carbaugh, 1998; Friedrich, 2016):

- $P R T_{(a c)}=0.15$ seconds for automated cooperative vehicles;

- $P R T_{(a a)}=0.30$ seconds for automated autonomous vehicles.

The Stopping Sight Distance (SSD) is a function of PRT:

$S S D=v \cdot P R T+\frac{v^{2}}{2 g \cdot\left(f_{e} \pm i\right)}$.

In which $v$ is the speed, $P R T$ is the perception-reaction time, $f_{e}$ is the longitudinal friction coefficient, $i$ is the slope of the road. By Eq. (2) we obtain:

- $S S D_{(m)}$ : stopping sight distance for manual driving vehicles (PRT calculated with Eq. (1));

- $S S D_{(a c)}$ : stopping sight distance for automated cooperative vehicles $\left(P R T_{(a c)}=0.15\right.$ seconds);

- $S S D_{(a a)}$ : stopping sight distance for automated autonomous vehicles ( $P R T_{(a a)}=0.30$ seconds).

The diagram in Figure 4a shows the values of the stopping sight distances as specified in the list, in function of the slope of the road. Two design speeds $\left(V_{p}\right)$ have been used: $V_{p, \min }=80 \mathrm{~km} / \mathrm{h}$ and $V_{p, \max }=140 \mathrm{~km} / \mathrm{h}$. On the other hand, the diagram in Figure $4 \mathrm{~b}$ illustrates the values $\Delta 1$ and $\Delta 2$ equal to the difference between the SSDs of manual driving vehicles, automated cooperative vehicles and automated autonomous vehicles. It follows that:

$$
\begin{aligned}
& \Delta 1=S S D_{(m)}-S S D_{(a c)}=v\left(P R T-P R T_{(a c)}\right)=v(2.8-0.01 \mathrm{~V}-0.15)=v(2.65-0.01 \mathrm{~V}) . \\
& \Delta 2=S S D_{(m)}-S S D_{(a a)}=v\left(P R T-P R T_{(a a)}\right)=v(2.8-0.01 \mathrm{~V}-0.30)=v(2.50-0.01 \mathrm{~V}) .
\end{aligned}
$$

In which $V$ denotes speed in $\mathrm{km}, v$ speed in $\mathrm{m} / \mathrm{s}$ and values $\Delta l$ and $\Delta 2$ are in metres. 


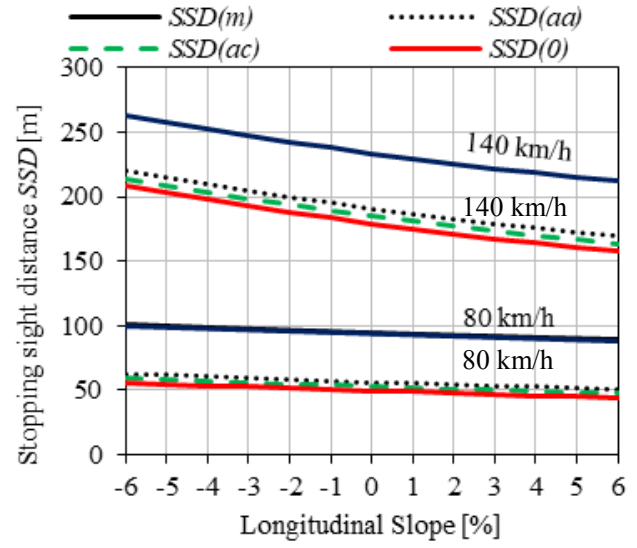

(a)

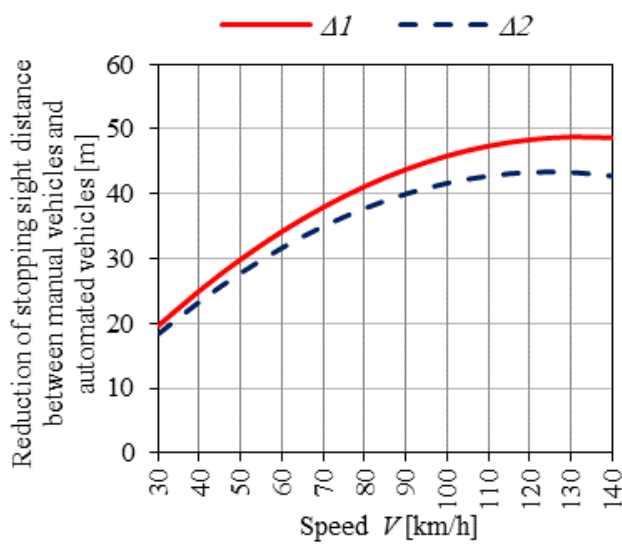

(b)

Figure 4. a) Stopping sight distance in function of the road slope $\left(S S D_{(m)}\right.$ : manual driving vehicles; $S S D_{(a c)}$ automated/cooperative vehicles; $S S D_{(a a)}$ automated/autonomous vehicles; $S S D_{(0)}$ theoretical values for $P R T=0 \mathrm{~s}$;

b) values $\Delta l$ and $\Delta 2$ in function of speed $V$

\subsection{Straights Design}

To avoid monotonous driving styles and the risk of being blinded at night by oncoming vehicles, in Italy the maximum straight length $\left(L_{s, \max }\right)$ should not exceed 22 times the maximum design speed of the $\operatorname{road} V_{p, \max }$ :

$L_{s, \max }=22 V_{p, \max }$.

Instead, for highways with flows of autonomous vehicles $L_{s, \max }=\infty$. In fact, the limits given from Equation (5) depend on human factors. In conformity with the German design guidelines, the minimum straight length between circular arcs curving in the same direction should be 6 times the design speed of the straight $L_{s, \min }=6 V_{p}$. As for the minimum length, a threshold level needs to be established so that the automated heavy vehicles exiting a curve can complete the rolling phase (for inertia) on the straight before entering the following curve. Thus, it is reasonable to adopt very precautionary values as those used in the railway engineering (RFI Guidelines), or:

$$
\left\{\begin{array}{l}
L_{s, \text { min }}=\frac{V_{p}}{3} \\
L_{s, \text { min }} \geq 30 \mathrm{~m}
\end{array} .\right.
$$

In which $V_{p}$ is the design speed for the straight.

The use of railway design criteria for designing geometric elements of smart road is adopted in other researches (Lambert et al., 2019). Table 3 compares the design and review criteria of the traditional infrastructures (D.M. n. 6792. 5/11/2001) with those of the infrastructures travelled by only automated vehicles.

Table 3. Design criteria for straights

\begin{tabular}{|c|c|c|c|}
\hline $\begin{array}{c}\text { Straights } \\
\text { design criteria }\end{array}$ & $\begin{array}{c}\text { Road for manually guided } \\
\text { vehicles }(100 \% \text { M.G. }\end{array}$ & $\begin{array}{c}\text { Road for manually guided and } \\
\text { autonomous guided vehicles } \\
\text { (M.G. and A.G.) }\end{array}$ & $\begin{array}{c}\text { Road for autonomous guided } \\
\text { vehicles (100\% A.G.) }\end{array}$ \\
\hline Maximum length & $L_{s . \max }=22 \cdot V p_{\max }$ & $L_{s . \max }=22 \cdot V_{p \max }$ & $\infty$ \\
\hline Minimum length & $L_{s, \min }=6 \cdot \mathrm{Vp}$ & $L_{s, \min }=6 \cdot V p$ & $\begin{array}{l}L_{S, \min }=\frac{V_{p}}{3} \\
L_{s, \min } \geq 30 \mathrm{~m}\end{array}$ \\
\hline
\end{tabular}

\subsection{Horizontal circular curve design}

The design of horizontal curves is based on a combination of design speed, curvature and superelevation, subject to the laws of physics and limitations of human comfort and tolerance. 
The radius of a circular arc is given by the following equation:

$\frac{V_{p}^{2}}{R}=127 \cdot\left(q+f_{t}\right)$.

In which: $V_{p}$ is the design speed of the curve in $\mathrm{km} / \mathrm{h}, R$ the radius in $\mathrm{m}, q$ the camber [\%] and $f_{t}$ is the tangential adhesion coefficient. Since it is an equilibrium condition which excludes human behaviour, the criterion remains unchanged also in case of infrastructures dedicated to the exclusive use of automated-guided vehicles. Based on the Italian guidelines, the current minimum length of a circular arc is $S_{v, \min }=2.5 \cdot V_{p} / 3.6$.

As regards the roads dedicated to automated-guided (A.G.) vehicles, a minimum development value needs to be set for travelling comfort. Indeed, it is indispensable for a heavy vehicle entering a curve to complete the rolling phase, for inertia, before entering the clothoid section (or the subsequent straight). To this end, it is reasonable to adopt the values used in the railway engineering (RFI Guidelines), or:

$$
\left\{\begin{array}{l}
S_{v, \text { min }}=\frac{V_{p}}{3} \\
S_{v, \text { min }} \geq 30 \mathrm{~m}
\end{array} .\right.
$$

Table 4 illustrates the comparison between design criteria for manually-driven road infrastructures (D.M. n. 6792. 5/11/2001) and for road infrastructures specifically designed to be only travelled by automated-guided vehicles.

Table 4. Design criteria for circular arcs

\begin{tabular}{|c|c|c|c|}
\hline $\begin{array}{c}\text { Design criteria for } \\
\text { circular arcs }\end{array}$ & $\begin{array}{c}\text { Road for manually-guided } \\
\text { vehicles }(100 \% \text { M.G.) }\end{array}$ & $\begin{array}{c}\text { Road for manually-guided and } \\
\text { automated-guided vehicles } \\
\text { (M.G. and A.G.) }\end{array}$ & $\begin{array}{c}\text { Road for automated- guided } \\
\text { vehicles (100\% A.G.) }\end{array}$ \\
\hline $\begin{array}{c}\text { Relationship among } \\
V_{p}, R, q \text { and } f_{t}\end{array}$ & $\frac{V_{p}^{2}}{R}=127 \cdot\left(q+f_{t}\right)$ & $\frac{V_{p}^{2}}{R}=127 \cdot\left(q+f_{t}\right)$ & $\frac{V_{p}^{2}}{R}=127 \cdot\left(q+f_{t}\right)$ \\
\hline minimum length & $S v_{\text {min }}=2.5 \cdot \frac{V_{p}}{3.6}$ & $S v_{\text {min }}=2.5 \cdot \frac{V_{p}}{3.6}$ & $\left\{\begin{array}{l}S_{v, \text { min }}=\frac{V_{p}}{3} \\
S\end{array}\right.$ \\
\hline
\end{tabular}

\subsection{Transition curve: design criteria for the clothoid}

As is well known, the clothoid equation is:

$A^{2}=R \cdot S$.

In which $A$ is the clothoid parameter and $R$ the radius at the end of the clothoid section with length denoted with $S$. In compliance to the Italian guidelines, the clothoid parameter must satisfy the following conditions:

$R \geq A \geq(A 1, A 2, A 3)$.

In which:

$$
\begin{array}{rlrl}
A 1 & =0.021 V_{p}^{2}, & & \text { (dynamic criterion) } \\
A 2=\sqrt{\frac{R_{f} \cdot B_{i} \cdot\left(q_{f}-q_{i}\right)}{\Delta i_{\max }}}, & & \text { (slope criterion) } \\
A 3 & =R / 3, & & \text { (optical criterion) }
\end{array}
$$

where:

$R$ is the radius at the end of the clothoid [m];

$B_{i}$ denotes the distance at the edge of the road from the rotation axis [m];

$q_{f}$ is the camber at the end of the clothoid;

$q_{i}$ is the camber at the beginning of the clothoid;

$\Delta_{\text {imax }}$ denotes higher or lower max gradient edge. 
The condition (10), $R \geq A$, is required in order to guarantee that the circular arc at the ending point of the clothoid is correctly perceived. Obviously, for driverless-vehicle roads and highways the conditions (10) and (13) are not compulsory. This means that, in this case, the limit is:

$A \geq(A 1, A 2)$.

Table 5 illustrates the Design criteria for clothoids.

Table 5. Design criteria for clothoids

\begin{tabular}{|c|c|c|c|}
\hline $\begin{array}{c}\text { Design criteria for } \\
\text { clothoids }\end{array}$ & $\begin{array}{c}\text { Road for manually-guided } \\
\text { vehicles }(100 \% \text { M.G. }\end{array}$ & $\begin{array}{c}\text { Road for manually-guided and } \\
\text { automated-guided vehicles (M.G. } \\
\text { and A.G.) }\end{array}$ & $\begin{array}{c}\text { Road for automated-guided } \\
\text { vehicles (100\% A.G.) }\end{array}$ \\
\hline Conditions & $A 2=\sqrt{\frac{R_{f} \cdot B_{i} \cdot\left(q_{f}-q_{i}\right)}{\Delta 1=0.021 V_{p}^{2}}}$ & $A 2=\sqrt{\frac{R_{f} \cdot B_{i} \cdot\left(q_{f}-q_{i}\right)}{\Delta i_{\text {max }}}}$ & $A 1=0.021 V_{p}^{2}$ \\
$A 3=R / 3$ & $A 3=R / 3$ & $\sqrt{\frac{R_{f} \cdot B_{i} \cdot\left(q_{f}-q_{i}\right)}{\Delta i_{\text {max }}}}$ \\
& $R \geq A \geq(A 1, A 2, A 3)$ & $R \geq A \geq(A 1, A 2, A 3)$ & $A 1, A 2)$ \\
\hline
\end{tabular}

\subsection{Gradients}

The maximum road gradient does not depend on human factors but only on vehicle performance and adhesion between tyre and asphalt pavement surface. Therefore, in case of automated-vehicle flows the maximum gradient is the same as in traditional roads with flows of manually-guided vehicles.

\subsection{Crest Vertical Curve Design}

Be $D$ the sight distance (Stopping sight distance or Passing sight distance), $h_{2}$ the target point height, $h_{l}$ the height of driver's eye point, $L$ the horizontal projection of the quadratic parabolas between a slope gradient variation $\Delta i$ and the minimum crest radius $R_{v}$. Following the Italian guidelines, $R_{v}$ is equal to:

$$
\begin{array}{ll}
R_{v}=\frac{D^{2}}{2 \cdot\left(h_{1}+h_{2}+2 \cdot \sqrt{h_{1} \cdot h_{2}}\right)}, & \text { if } D<L \\
R_{v}=\frac{2}{\Delta i} \cdot\left(D-\frac{h_{1}+h_{2}+2 \cdot \sqrt{h_{1} \cdot h_{2}}}{\Delta i}\right), & \text { if } D>L
\end{array}
$$

$h_{1}$ and $h_{2}$ are respectively equal to $1.10 \mathrm{~m}$ and $0.10 \mathrm{~m}$.

For automated vehicles, as stopping sight distance values are lower than those required for manually-guided vehicles, crest radii $R_{v}$ should be much smaller than those traditionally used on common roads. Moreover the road network analysis system is performed with LiDAR, Radar, surveillance video cameras mounted on the roofs of automated vehicles. Therefore, for this type of vehicles $h_{1}>1.10 \mathrm{~m}$ with further reduction in $R_{v}$ values. Table 6 illustrates the design criteria for crest vertical curves.

Table 6. Design criteria for crest vertical curves

\begin{tabular}{|c|c|c|c|}
\hline $\begin{array}{c}\text { Design criteria for } \\
\text { crest vertical curves }\end{array}$ & $\begin{array}{c}\text { Road for manually- } \\
\text { guided vehicles } \\
(100 \% \text { M.G. })\end{array}$ & $\begin{array}{c}\text { Road for manually-guided } \\
\text { and automated-guided } \\
\text { vehicles (M.G. and A.G.) }\end{array}$ & $\begin{array}{c}\text { Road for automated-guided vehicles } \\
(100 \% \text { A.G.) }\end{array}$ \\
\hline $\begin{array}{c}h_{1}=1.10 \mathrm{~m} \\
h_{2}=0.10 \mathrm{~m}\end{array}$ & $\begin{array}{c}h_{1}=1.10 \mathrm{~m} \\
h_{2}=0.10 \mathrm{~m} \\
D=S S D(v ; P R T) \\
\text { Conditions for } \\
\text { stopping sight distance }\end{array}$ & $\begin{array}{c}D=S S D(v ; P R T) \\
\text { with } P R T=2.8-0.01 \mathrm{~V}\end{array}$ & $\begin{array}{c}h_{1}>>1.10 \mathrm{~m} \\
h_{2}=0.10 \mathrm{~m}\end{array}$ \\
$(D=S S D)$ & $\begin{array}{c}\text { automated autonomous vehicles: } D=S S D_{(a)} \\
\text { automated cooperative vehicles } D=S S D_{(a c)}\end{array}$ \\
\hline
\end{tabular}

\subsection{Sag Vertical Curve Design}

The Sag Vertical Curve Design considers the ability of a vehicle to stop safely in front of an obstacle identified by headlights (Kuhn, 2013). The threshold radius is calculated with the formula: 


$$
R_{v}=\frac{2}{\Delta i} \cdot\left(D-\frac{h+D \cdot \vartheta}{\Delta i}\right) .
$$

In which $h$ is the headlights height $(h=0.5 \mathrm{~m})$ and $\vartheta$ is the headlights divergence $\left(\vartheta=1^{\circ}\right)$.

The automated guided vehicles can scan the road track by means of LiDAR, Radar and Video cameras, thus being potentially unaffected by road light conditions significantly. Thus, sag vertical curves should guarantee travellers comfortable conditions. By assuming the maximum vertical acceleration $a_{v, \max }=0.6 \mathrm{~m} / \mathrm{s}^{2}$, the following relation must be satisfied:

$$
R_{v} \geq \frac{v^{2}}{0.6}=1.67 \cdot v^{2}=0.129 \cdot \mathrm{V}^{2} .
$$

Table 7 shows the design criteria for sag vertical curves.

\begin{tabular}{|c|c|c|c|}
\hline $\begin{array}{l}\text { Design criteria for } \\
\text { sag vertical curves }\end{array}$ & $\begin{array}{l}\text { Road for manually-guided vehicles } \\
\qquad(100 \% \text { M.G.) }\end{array}$ & $\begin{array}{l}\text { Road for manually-guided } \\
\text { and automated-guided } \\
\text { vehicles (M.G. and A.G.) }\end{array}$ & $\begin{array}{l}\text { Road for automated- guided } \\
\text { vehicles (100\% A.G.) }\end{array}$ \\
\hline $\begin{array}{c}\text { Conditions for } \\
\text { stopping sight } \\
\text { distance }(D=S S D)\end{array}$ & $\begin{array}{c}h_{l}=1.10 \mathrm{~m} \\
h_{2}=0.10 \mathrm{~m} \\
S S D=S S D(v ; P R T) \\
R_{v}=\frac{2}{\Delta i} \cdot\left(S S D-\frac{h+S S D \cdot \vartheta}{\Delta i}\right)\end{array}$ & $\begin{array}{c}h_{1}=1.10 \mathrm{~m} \\
h_{2}=0.10 \mathrm{~m} \\
S S D=S S D(v ; P R T) \\
P R T=2.8-0.01 \mathrm{~V}\end{array}$ & $R_{v} \geq 0.129 \cdot V^{2}$ \\
\hline
\end{tabular}

Table 7. Design criteria for sag vertical curves

\section{Criterion for estimating capacity increase due to automated guided vehicles}

As is well known, in a homogeneous traffic flow the vehicle density $k$ is the reciprocal of the mean space headway between pairs of vehicles (Ioannou, 1997; Elefteriadou, 2014):

$k=\frac{1}{T_{v} \cdot V+L}$.

In which $T_{v}$ denotes the mean time headway, $V$ is the flow speed and $L$ the mean distance between pairs of vehicles. In capacity conditions, $T_{v}$ may assume the following values (Carbaugh, 1998; Friedrich, 2106; Funkhouser, 2016; Dixit, 2016):

- manually guided vehicles: it cannot fall below the perception-reaction time, here denoted with $T_{m}$. Or: $T_{v}=T_{m}=1.15$ seconds;

- automated cooperative vehicles: $T_{v}=P R T_{(a c)}=0.15$ seconds;

- automated autonomous vehicles $T_{v}=P R T_{(a)}=0.30$ seconds.

Nevertheless, as a precautionary measure, all automated guided vehicles are assumed to have a value higher than and equal to $T_{v}=T_{a}=0.5$ seconds.

By particularising relation (19), both the capacity for a flow consisting of only vehicles with human control $C_{m}$ and the capacity for a flow made up of only automated vehicles $C_{a}$ (Friedrich, 2106) can be obtained as follows:

$$
\begin{aligned}
& C_{m}=\frac{V}{T_{m} \cdot V+L} \\
& C_{a}=\frac{V}{T_{a} \cdot V+L} .
\end{aligned}
$$

The ratio $\chi$ of the two capacity values is worked out by the relation:

$$
\chi=\frac{C_{a}}{C_{m}}=\frac{T_{m} \cdot V+L}{T_{a} \cdot V+L} .
$$

The following mean values can be used for the intravehicular space distance:

- passenger car $L=L_{\text {car }}=7.5 \mathrm{~m}(4.5 \mathrm{~m}$ mean vehicle length $+3 \mathrm{~m}$ minimum safety distance to the vehicle ahead);

- truck $L=L_{\text {truck }}=21 \mathrm{~m}(18 \mathrm{~m}$ mean vehicle length $+3 \mathrm{~m}$ minimum safety distance to the vehicle ahead). 
For the flow capacity conditions, the mean vehicle speed is the so called critical flow speed $\left(V=V_{c}\right)$. Denoting heavy traffic proportion with $\omega$, the previous expressions (20), (21) and (22) can be particularised as follows (Friedrich, 2106):

$$
\begin{aligned}
& C_{m}=\frac{V}{(1-\omega) \cdot\left(T_{m} \cdot V+L_{c a r}\right)+\omega \cdot\left(T_{m} \cdot V+L_{\text {truck }}\right)} . \\
& C_{a}=\frac{V}{(1-\omega) \cdot\left(T_{a} \cdot V+L_{c a r}\right)+\omega \cdot\left(T_{a} \cdot V+L_{\text {truck }}\right)} . \\
& \chi=\frac{C_{a}}{C_{m}}=\frac{(1-\omega) \cdot\left(T_{m} \cdot V+L_{c a r}\right)+\omega \cdot\left(T_{m} \cdot V+L_{\text {truck }}\right)}{(1-\omega) \cdot\left(T_{a} \cdot V+L_{c a r}\right)+\omega \cdot\left(T_{a} \cdot V+L_{\text {truck }}\right)} .
\end{aligned}
$$

Lane capacity increases in function of speed and for varied $\omega$ values are charted in Figure 5a.

Before that, homogeneous flows, i.e. composed of only manually guided vehicles (100\% M.G.) or automated guided vehicles (100\% G.A.), were examined and compared between them. In mixed traffic, denoting with $\eta$ the share of autonomous vehicles in the total volume $(0 \leq \eta \leq 1)$, the lane capacity obtained from Equation (25) (Friedrich, 2106) is:

$$
C_{m i x}=\frac{V}{\eta \cdot V \cdot T_{a}+(1-\eta) \cdot V \cdot T_{m}+L} .
$$

In mixed traffic the vehicle pairs following one another in the traffic flow can be made up of a combination of successive manually guided (M.G.) and automated guided (A.G.) vehicles. The actual headways for each combination are:

- M.G.- M.G. and M.G.-A.G. $T_{m, x}=T_{m}=1.15$ seconds;

- A.G.- A.G. $T_{a, a}=0.5$ seconds;

- A.G.- M.G. $T_{a, m}=0.9$ seconds (in order to prevent A.G. vehicle from travelling too close to M.G., thus disturbing the driver).

By denoting with $L$ the mean vehicle length, we have (Friedrich, 2106):

$$
C_{m i x}=\frac{V}{\eta^{2} \cdot V \cdot T_{a, a}+\eta \cdot(1-\eta) \cdot V \cdot T_{a, m}+(1-\eta) \cdot V \cdot T_{m, x}+L} .
$$

The ratio $\chi$ between the lane capacity with mixed traffic rate $\eta$ and the lane capacity with only manually guided vehicles (Figure 5 b) is (Friedrich, 2106):

$$
\chi=\frac{C_{m i x}}{C_{m}}=\frac{T_{m} \cdot V+L}{\eta^{2} \cdot V \cdot T_{a, a}+\eta \cdot(1-\eta) \cdot V \cdot T_{a, m}+(1-\eta) \cdot V \cdot T_{m, x}+L} .
$$

With $T_{m}=T_{m, x}=1.15$ seconds and $V=V_{c}$ critical speed for a road infrastructure used only by human drivers (100\% M.G).

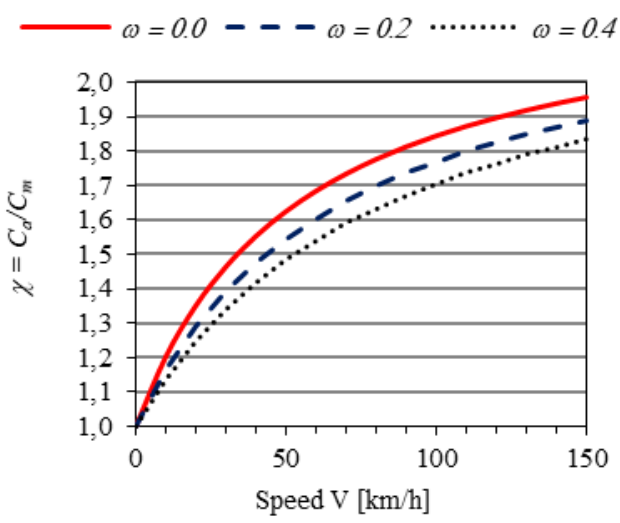

(a)

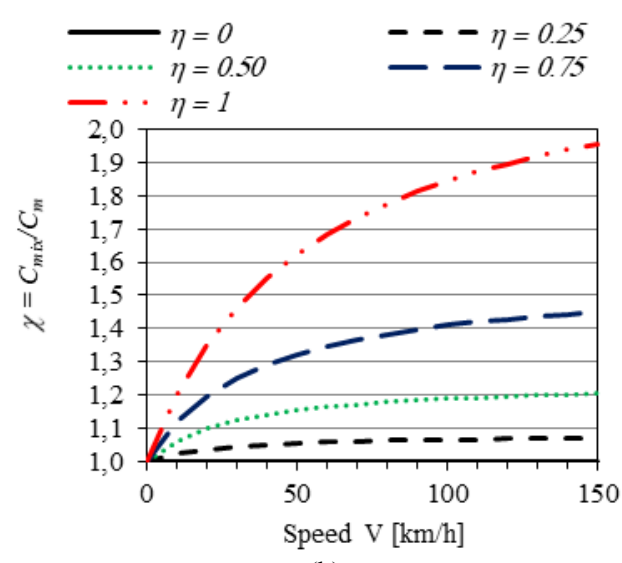

(b)

Figure 5. a) Capacity increase in a mixed-flow lane with automated guided vehicles against capacity value in a flow composed of manually guided vehicles and referred to different heavy vehicle percentages $(\omega)$;

b) Capacity increase in a lane with different rate $\eta$ of automated guided vehicles against the total (vehicle length $L=7.5 \mathrm{~m}$ ) 


\section{Case study: the A22 Brenner Motorway}

The A22 Brenner motorway is part of the trans-European road network TEN-T (specifically the Scandinavian-Mediterranean corridor (Regulation (EU) N. 1316/2013). In Italy the infrastructure links the cities of Bolzano, Trento, Verona and Modena. It is connected to the A13 Brenner Autobahn in Austria. The A22 function is then crucial to European transport. The A22 Brenner motorway is 313-km long and has 24 toll booths, 4 junctions with other Italian motorways (A4 West, A4 East, A1 North and A1 South). The road has two lanes (3.75-m wide each) in every direction and right-hand hard shoulders (3.45 m-wide each), separated by a 1.20 m-wide central reservation.

\subsection{Safety condition assessment of automated traffic flows}

Comprehensive data on straights, circular curves, gradients and vertical curves of the A22 motorway are shown in Tables 8,9 and 10 .

Table 8. Main characteristics of straights

\begin{tabular}{|c|c|c|c|c|}
\hline \multicolumn{5}{|c|}{ Straigthts } \\
\hline No. & $L_{\min }[\mathrm{m}]$ & $L_{\max }[\mathrm{m}]$ & $V_{p, \min }[\mathrm{km} / \mathrm{h}]$ & $V_{p, \max }[\mathrm{km} / \mathrm{h}]$ \\
\hline 304 & 1.55 & $3,330.69$ & 82.6 & 140.0 \\
\hline
\end{tabular}

Table 9. Main characteristics of circular curves

\begin{tabular}{|l|c|c|c|c|c|c|c|}
\hline \multicolumn{2}{|c|}{ Circular curves } \\
\hline No. & $R_{\min }[\mathrm{m}]$ & $R_{\max }[\mathrm{m}]$ & $V_{p, \min }[\mathrm{km} / \mathrm{h}]$ & $V_{p, \max }[\mathrm{km} / \mathrm{h}]$ & $q_{\max }[\%]$ & $S_{v, \min }[\mathrm{m}]$ & $S_{v, \max }[\mathrm{m}]$ \\
\hline 304 & 300 & 10,000 & 82.2 & 140.0 & 5 & 29.83 & $2,1088.83$ \\
\hline
\end{tabular}

Table 10. Main characteristics of gradients and vertical curves

\begin{tabular}{|c|c|c|c|c|c|c|}
\hline \multicolumn{8}{|c|}{ Gradients and vertical curves } \\
\hline No. & $i_{\min }[\%]$ & $i_{\max }[\%]$ & $L_{\min }[\mathrm{m}]$ & $L_{\max }[\mathrm{m}]$ & $R v_{\min }[\mathrm{m}]$ & $R v_{\max }[\mathrm{m}]$ \\
\hline 415 & 0 & 3.79 & 108.12 & $3,250.68$ & 3,000 & 45,000 \\
\hline
\end{tabular}

The new design and review criteria provided in the previous Section 2 were implemented in a new specially developed software, named "HSA v.2019a" (HAS v.2019a, 2019). The conformity of the A22 motorway (from $\mathrm{km} 0+000$ to $\mathrm{km} 313+061.62$ ) to the new geometrical criteria designed for roads travelled by automated guided vehicles was examined with detailed regard to its horizontal and vertical alignment. The substantial A22 conformity to the criteria described in the previous Sections was observed with the only exception of some minimum lengths of straights. However, some "short" straights are not a safety problem, but rather they may lower driving comfort. In safety terms, indeed, automated vehicles will be able to adjust their speed before arriving at such "short" straights, thanks to the systems for information communication and exchange data between infrastructure and vehicles (V2I and I2V systems), some of which already installed in the course of the C-Roads project. Finally, it was established that in both A22 directions (Figure 6 and Figure 7) automated guided vehicles will require shorter stopping sight distances (calculated in function of the design speed in each highway section and the slope) than those required by manually guided vehicles nowadays. This could help to eliminate many speed limits in some motorway segments, due to visibility obstacles (e.g. small radius curves, presence of safety barriers, threes, etc.).

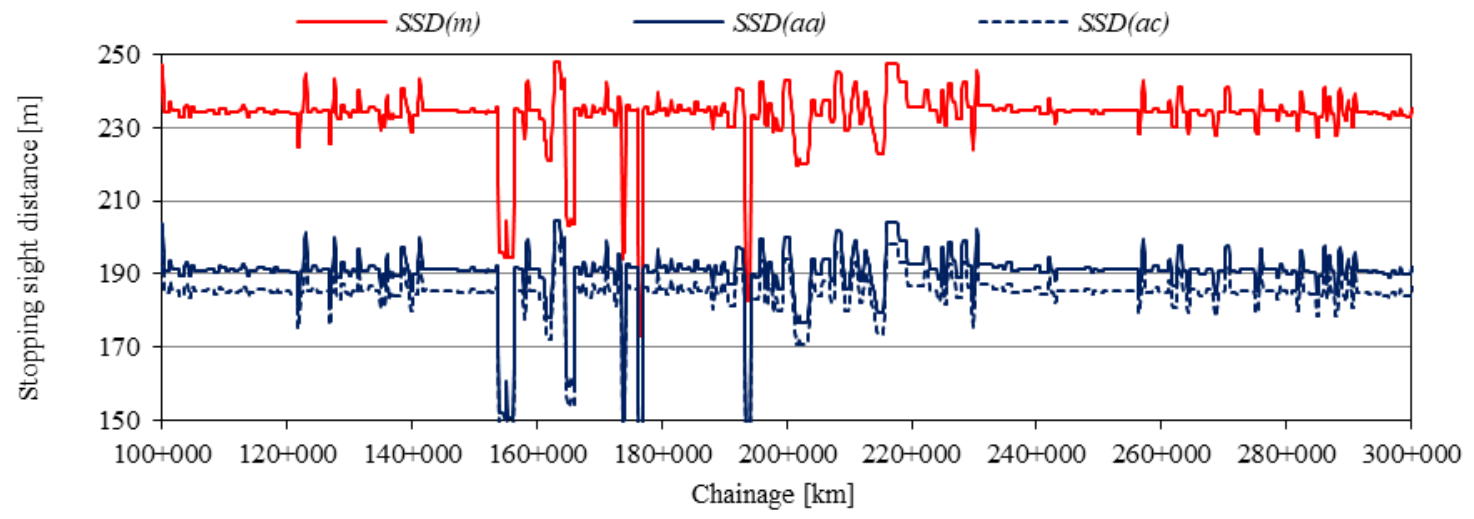

Figure 6. Stopping sight distance for manually guided and automated vehicles (direction 1: from north to south; motorway segment from km 100 to $\mathrm{km} \mathrm{300)}$ 


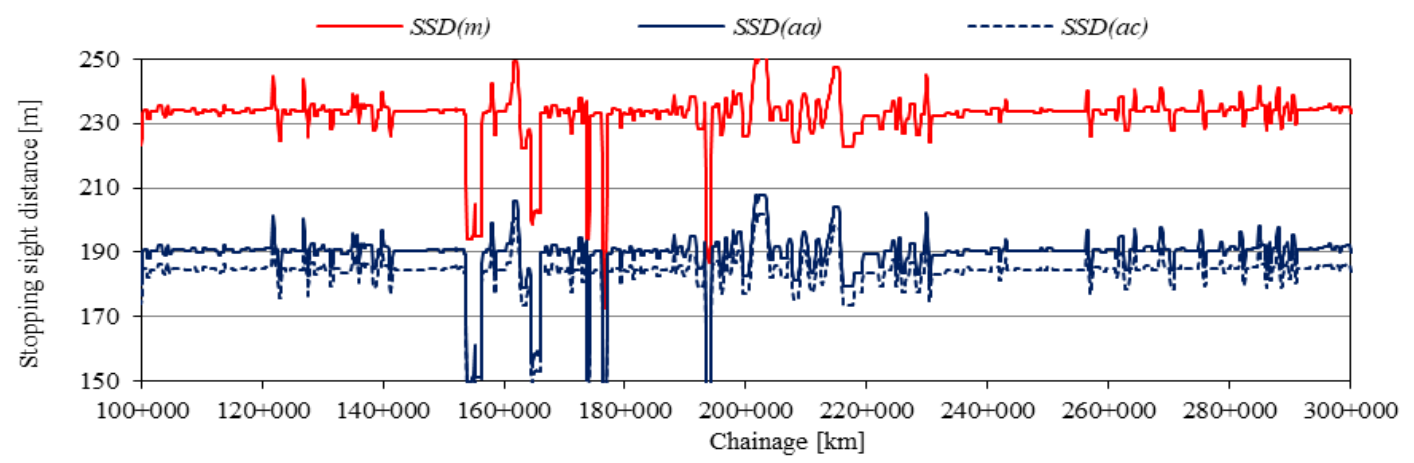

Figure 7. Stopping sight for manually guided and automated vehicles (direction 2: from south to north; motorway segment from $\mathrm{km} 100$ to $\mathrm{km} \mathrm{300)}$

\subsection{Estimation of capacity increase due to flows with automated guided vehicles}

In order to get the value of the capacity increase due to automated guided flows, the current capacity values for driving, overtaking and carriageway lanes were estimated preliminarily.

Thus, traffic data were observed in four crucial sections of the A22 motorway:

- Kofler, km 063+500;

- S. Michele, km 123+960;

- Portale Affi, km 205+500;

- Mantua, km 271+900.

The macroscopic flow parameters - flow $q$; speed $v$ (harmonic mean speed); density $k$ - were calculated with reference to 5-min time intervals. The vehicles were homogenised by using the HCM 2010 passenger car equivalent factors PCEs (the flows are then expressed in $\mathrm{pcu} / \mathrm{h}$ ). The numerousness of pairs $(v ; k),(q ; k),(v ; q)$, determined in intervals $\Delta \mathrm{T}=5$ minutes, is shown in Table 11 . The total numerousness is $\mathrm{N}_{5}=24,192$.

Table 11. Number of pairs $(v ; k),(q ; k),(v ; q)$

\begin{tabular}{|c|c|c|c|c|c|c|c|}
\hline $\begin{array}{c}\text { San Michele } \\
123+960 \\
\text { North }\end{array}$ & $\begin{array}{c}\text { San Michele } \\
123+960 \\
\text { South }\end{array}$ & $\begin{array}{c}\text { Kofler } \\
063+500 \\
\text { North }\end{array}$ & $\begin{array}{c}\text { Kofler } \\
063+500 \\
\text { South }\end{array}$ & $\begin{array}{c}\text { Portale Affi } \\
205+500 \\
\text { North }\end{array}$ & $\begin{array}{c}\text { Portale Affi } \\
205+500 \\
\text { South }\end{array}$ & $\begin{array}{c}\text { Mantua } \\
271+900 \\
\text { North }\end{array}$ & $\begin{array}{c}\text { Mantua } \\
271+900 \\
\text { South }\end{array}$ \\
\hline 4032 & 4032 & 4032 & 4032 & 2016 & 2016 & 2016 & 2016 \\
\hline
\end{tabular}

By means of the collected traffic data, the Drake model was calibrated with the least-square method (May, 1990; Guerrieri and Mauro, 2016) in that it turned out to be the best model for interpreting the available data. For more details about this model calibration, the interested reader may consult Guerrieri and Mauro, 2016. The Drake relation is: $v=v_{f} \exp \left[-0.5 \cdot\left(k / k_{j a m}\right)^{2}\right]$, in which $v_{f}$ is the free-flow speed and $k_{j a m}$ is the maximum density (or jam density).

Through this relation and the fundamental flow law $q=k \cdot v$, the other flow relations $v=v(q)$, $q=q(k)$ can be inferred. Thus, the flow relations $v=v(q), q=q(k), v=v(k)$ were worked out for each prominent section, being $\mathrm{v}$ the space mean speed, $q$ the flow and $k$ the density. In mean, relations for the entire A22 motorway were also inferred. Figure 8 specifically shows the relations $q=q(k)$ and $v=v(q)$.

Table 12. Traffic flow parameters (free flow speed $v_{f l}$, critical density $k_{c}$, capacity $C$ and critical speed $v_{c}$ )

\begin{tabular}{|c|c|c|c|c|}
\hline Carriageway lane & $v_{f f}[\mathrm{~km} / \mathrm{h}]$ & $k_{c}[\mathrm{pcu} / \mathrm{lane} / \mathrm{km}]$ & $C[\mathrm{pcu} / \mathrm{h}]$ & $v_{c}[\mathrm{~km} / \mathrm{h}]$ \\
\hline Right lane & 106 & 24 & 1,552 & 65 \\
\hline Overtaking lane & 128 & 25 & 1,916 & 77 \\
\hline Carriageway & 115 & 47 & 3,254 & 70 \\
\hline
\end{tabular}

By means of the traffic model described in previous Sections above and the current capacity estimations (Table 12, cfr. Guerrieri and Mauro, 2016), the expected capacity increases in single (overtaking and driving) lanes can be deduced as the rate $\eta$ referred to the flow composed of automated guided vehicles against the total $(0 \leq \eta \leq 1)$. The study of the current A22 operational conditions has allowed estimating the following average values referred to capacity $C$ and critical speed $v_{c}$ (see Table 12):

- Right lane $\quad C=C_{m}=1,552 \mathrm{pcu} / \mathrm{h} ; v_{c}=65 \mathrm{~km} / \mathrm{h}$.

- Overtaking lane $C=C_{m}=1,916 \mathrm{pcu} / \mathrm{h} ; v_{c}=77 \mathrm{~km} / \mathrm{h}$.

Expression (27) can be used to calculate, for each lane, the theoretical capacity value with mixed traffic $C_{m i x}$ and the ratio $\chi$ between such a theoretical capacity and that inferred empirically as in the current traffic conditions (100\% manually guided vehicles). For the right lane the performance of capacity 
and ratio $\chi$, calculated for $V_{c}=65 \mathrm{~km} / \mathrm{h}$ and $L=7.5 \mathrm{~m}$ are respectively diagrammed in Figure 9 . For automated guided vehicles $\eta=1$, a maximum capacity of around 3,933 pcu/h is obtained against the current $1,552 \mathrm{pcu} / \mathrm{h}$. For the overtaking lane, the capacity and ratio $\chi$ calculated for $v_{c}=77 \mathrm{~km} / \mathrm{h}$ and $L=7.5 \mathrm{~m}$ are respectively diagrammed in Figure 10 in function of $\eta$. For automated guided vehicles $\eta=1$, a maximum capacity of $4,232 \mathrm{pcu} / \mathrm{h}$ is obtained against the current $1,916 \mathrm{pcu} / \mathrm{h}$.

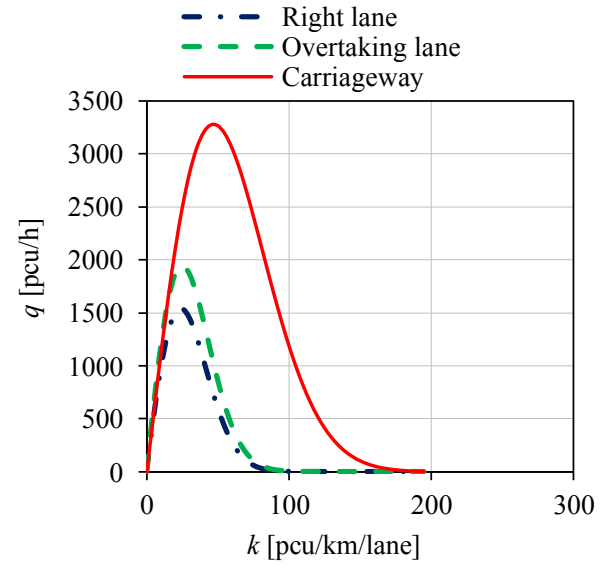

(a)

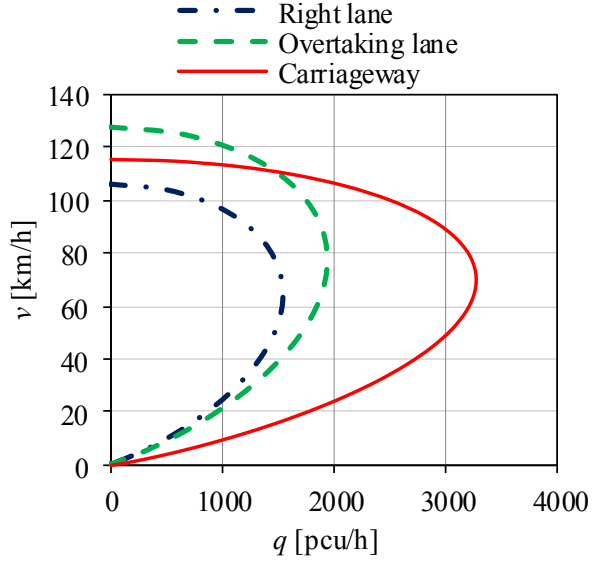

(b)

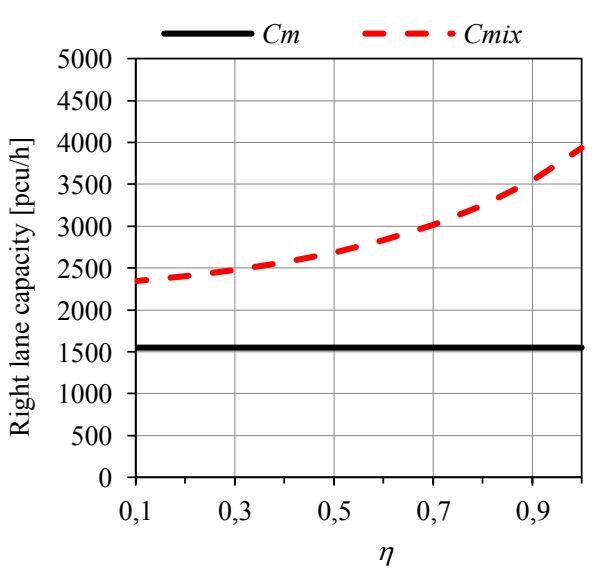

(a)

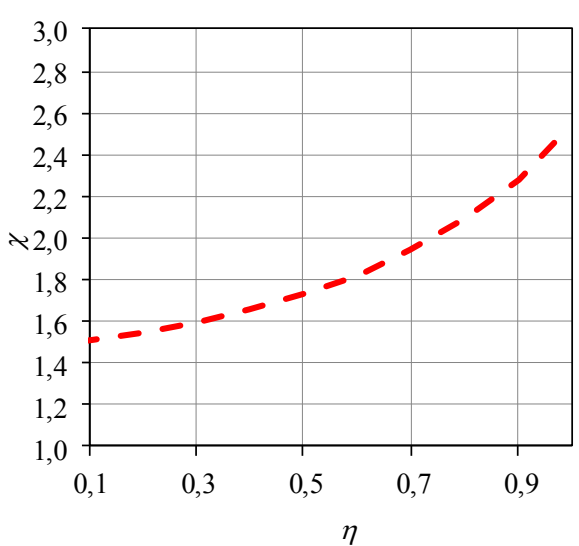

(b)

Figure 9. Right lane - a) comparison between the current $\left(C_{m}\right)$ and the theoretical $\left(C_{m i x}\right)$ capacities for mixed flow (M.G. and A.G.), when the rate $\eta$ of automated guided vehicles varies; b) ratio $\chi=C_{m i x} / C_{m}$

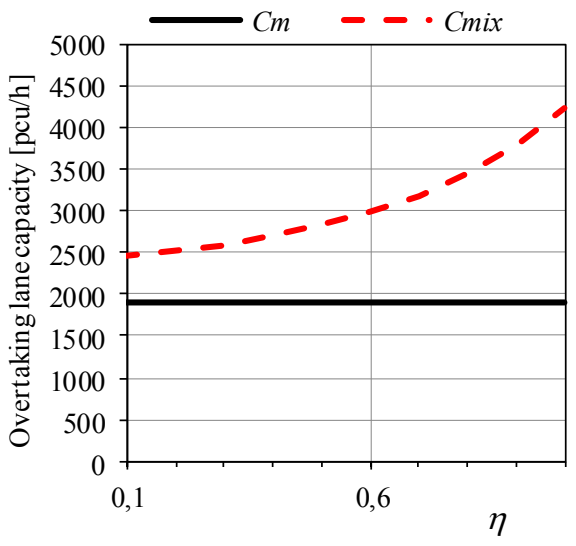

(a)

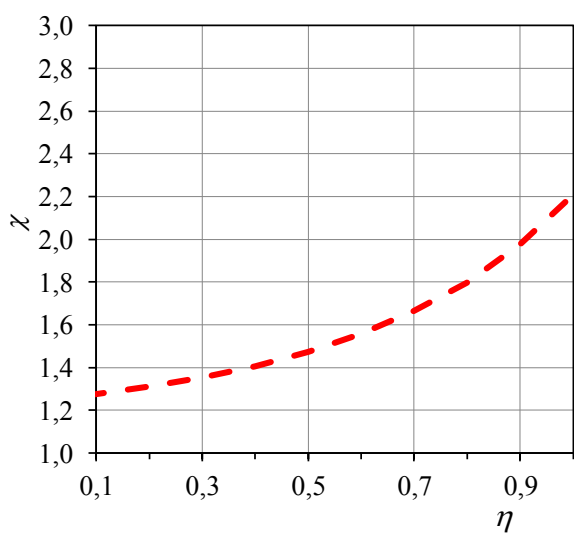

(b)

Figure 10. Overtaking lane - a) comparison between the current $\left(C_{m}\right)$ and the theoretical $\left(C_{m i x}\right)$ capacities for mixed flow (M.G. and A.G.), when the rate $\eta$ of automated guided vehicles varies; b) ratio $\chi=C_{m i x} / C_{m}$ 


\section{Conclusions}

Thanks to the C-Roads Platform, several European highway operators are carrying out research on topics related to cooperative intelligent transport systems (C-ITS). This research aims first at implementing C-ITS systems so as to provide Day $1 \mathrm{C}$-ITS services. Other researches are intended for introducing automated guided (Levels 4 and 5) vehicles onto European roads in terms of both communication technologies and anticipation models of safety and functionality conditions in highway infrastructures. With special regard to the two aspects above, this research has proposed some design and review criteria for horizontal and vertical alignment of road infrastructures, to be used for testing the compatibility between the existing infrastructures and flows composed of automated guided vehicles. Such criteria were obtained from those traditionally employed in the highway engineering. The Italian A22 motorway being of great interest, the design criteria applied in Italy were particularised, so as to take functional and performance characteristics of automated guided vehicles into account.

The following three modes of infrastructure use were considered:

- Highways exclusively devoted to manually guided (M.G.) vehicles, or 100\% M.G.

- Highways exclusively devoted to mixed traffic, i.e. composed of both manually guided (M.G.) and automated guided (A.G.) vehicles;

- Highways exclusively devoted to automated guided (A.G.) vehicles, or $100 \%$ A.G.

Then the conformity of horizontal and vertical alignment of the A22 motorway (from $\mathrm{km} 0+000$ to $\mathrm{km} 313+061.62$ ) was assessed against the new geometrical criteria designed for roads with automated guided vehicles. Through the use of a software called "HSA v.2019a", developed in a Matlab environment, the plano-altimetric alignment of the A22 motorway resulted to be substantially conform to such criteria (that have been implemented in the software "HSA v.2019a"), with the only exception of the minimum length of some straights. In both A22 directions automated guided vehicles proved to need much shorter stopping sight distances (calculated in function of the design speed and the slope) than those today required by manually guided vehicles. This may eliminate many speed limits along some motorway segments, due to visibility obstacles (e.g. small radius curves and presence of safety barriers).

Another field of research was devoted to estimate motorway capacity with reference to the mixed traffic composed of different rates of autonomous and manually guided vehicles. A specific traffic model was used to consider the effect of the mutual minimum distance between vehicle pairs following each other in a mixed vehicle flow, with special regard to different sequence of manually guided (M.G.) and automated guided (A.G.) vehicles. The minimum time headways, which guarantee safety and can be associated to the different vehicle pairs, were obtained by the most recent state-of-the-field scientific literature. It resulted that:

- Minimum headway between M.G.-M.G. vehicles and M.G.-A.G. vehicles = 1.15 seconds;

- Minimum headway between A.G.-A.G. vehicles = 0.5 seconds;

- Minimum headway between A.G.-M.G. $=0.9$ seconds (higher than the previous value, in that A.G. vehicles are not to drive too close to M.G. vehicles so as to avoid inconvenience to their drivers in terms of safety and comfort).

The proposed traffic model makes it possible to calculate the capacity $\left(C_{m i x}\right)$ of a mixed-flow lane when speed, average vehicle length $L$ and rate $\eta$ of automated guided vehicles vary. Clearly, the limit of the suggested model is its being theoretical and as such impossible to be validated or calibrated for lack of empirical data, in that the extensive use of automated guided vehicles is not widespread yet. Such a theoretical capacity value $\left(C_{m i x}\right)$ was then compared to the capacity obtained from the current conditions of use of highways, i.e. for "traditional" manually guided vehicles $\left(C_{m}\right)$. To this end, the values of the lane capacity and critical speed were used after previously processing the traffic surveys conducted in four different A22 motorway sections. For the current conditions of use, the following capacity values were obtained:

- Driving lane: $C_{m}=1,552 \mathrm{pcu} / \mathrm{h} ; V_{c}=65 \mathrm{~km} / \mathrm{h}$;

- Overtaking lane: $C_{m}=1,916 \mathrm{pcu} / \mathrm{h} ; V_{c}=77 \mathrm{~km} / \mathrm{h}$.

Noticeably, the use of automated guided vehicles will increase the highway performances. This because the mixed-flow capacity $\left(C_{m i x}\right)$ increases monotonously with the rate $\eta$ of automated guided vehicles. More specifically, the maximum value of $C_{m i x}$ - calculated for velocity equal to that used for the current capacity value (i.e. for $V=V_{c}$ ) - is obtained for $\eta=1$, i.e. for a flow composed only of automated guided vehicles (100\% A.G. vehicles). The following results were obtained:

- Right lane: maximum capacity $C_{\text {mix }}=3,933 \mathrm{pcu} / \mathrm{h}$, against the current $1,552 \mathrm{pcu} / \mathrm{h}$ (ratio between the future and the current capacities $\chi=C_{m i x} / C_{m} \approx 2.5$ );

- Overtaking lane: maximum capacity $C_{m i x}=4,232 \mathrm{pcu} / \mathrm{h}$, against the current $1,916 \mathrm{pcu} / \mathrm{h}$ (ratio between the future and current capacities $\chi=C_{m i x} / C_{m} \approx 2.2$ ). 
In conclusion, the lane capacity in the A22 motorway is undoubtedly bound to increase more and more with the growing percentage $\eta$ of automated guided vehicles. In agreement with the results of this study, in the long term (that is, when all vehicles will be automated guided) the values of the lane capacity and carriageway will be more than double the current values and, on the whole, the infrastructure will provide also adequate safety levels for new driverless vehicles.

\section{Acknowledgments}

The Authors wish to thank Dr. Eng. Walter Pardatscher, and Dr. Eng Carlo Costa, CEO and General Technical Director of the "Autostrada del Brennero SpA" respectively, for their contribution to the development of the research.

\section{References}

1. Berktaş, E. Ş., Tanyel, S. (2020) Effect of Autonomous Vehicles on Performance of Signalized Intersections. Journal of Transportation Engineering Part A: Systems, 146(2). Available: https://doi.org/10.1061/JTEPBS.0000297

2. Carbaugh, J., Godbole, D. N., Sengupta, R. (1998) Safety and capacity analysis of automated and manual highway systems. Transportation Research Part C: Emerging Technologies, 6, 69-99.

3. C-Roads Plataform. Available: https://www.c-roads.eu/platform/about/about.html

4. Guidelines for the Design of Road Infrastructures (2001) D.M. n. 6792. 5/11/2001. Italian Ministry of Infrastructures and Transports, Rome, Italy.

5. Dixit, V. V., Chand, S., Nair, D. J. (2016) Autonomous Vehicles: Disengagements, Accidents and Reaction Times. PLOS ONE, 20, 1-14.

6. Elefteriadou, L. (2014) An Introduction to Traffic Flow. Springer.

7. Friedrich, B. (2016) The Effect of Autonomous Vehicles on Traffic. In: Maurer M., Gerdes J., Lenz B., Winner H. (eds) Autonomous Driving. Springer.

8. Funkhouser, K., Drews, F. (2016) Reaction Times When Switching from Autonomous to Manual Driving Control: A Pilot Investigation. Proceedings of the Human Factors and Ergonomics Society, Annual Meeting.

9. Gordon, R. (2010) Intelligent Freeway Transportation Systems. Springer.

10. Guerrieri, M. and Mauro, R. (2016) Capacity and safety analysis of hard-shoulder running (HSR), A motorway case study. Transportation Research Part A: Policy and Practice, 92, 162-183.

11. Guerrieri, M., Corriere, F., Rizzo, G., Lo Casto, B., Scaccianoce, G. (2015) Improving the sustainability of transportation: Environmental and functional benefits of right turn by-pass lanes at roundabouts. Sustainability, 7(5), 5838-5856.

12. HAS v.2019a (Highway safety analysis for automated vehicles). (2019) Available: https://sites.google.com/view/h-s-a-v-2018a/home.

13. Ioannou, A. (1997) Automated Highway Systems. Springer.

14. Kuhn, W. (2013) Fundamentals of road design. Wit Press.

15. Lambert, E.D., Romano, R., Watling, D. (2019) Optimal path planning with clothoid curves for passenger comfort. Proceedings of the 5th International Conference on Vehicle Technology and Intelligent Transport Systems, VEHITS 2019; Heraklion, Crete; Greece; 3-5 May 2019.

16. Lerner, L. D. (1993) Brake perception-reaction times of older and younger drivers. Proceedings of the human factors and ergonomics society 37 th annual meeting.

17. May, A. D. (1990) Traffic Flow Fundamentals. Prentice-Hall.

18. NCHRP, Report 600 (2012) Human Factors Guidelines for Road Systems, Second Edition. Transportation Research Board. National Cooperative Highway Research Program.

19. Papageorgiou, M., Hadj-Salem, H., Blosseville, J. M. (1991) ALINEA: A Local Feedback Control Law for On-Ramp Metering. Transportation Research Record, 1320, 58-64.

20. Regulation (EU) No 1316/2013 of the European Parliament and of the Council of 11 December 2013 establishing the Connecting Europe Facility, amending Regulation (EU) No 913/2010 and repealing Regulations (EC) No 680/2007 and (EC) No 67/2010.

21. RFI Guidelines. Guidelines for the Design of Railway Infrastructures. RFI S.p.A. (code: RFI TCAR IT AR $01001 \mathrm{~A})$.

22. Sens, M., Cheng, P., Wiechel, J., Guenther, D. (1989) Perception/Reaction Time Values for Accident Reconstruction. SAE Technical Paper 890732. Available: https://doi.org/10.4271/890732.

23. Tollazzi, T., Mauro, R., Guerrieri, M., Renčelj, M. (2016) Comparative analysis of four new alternative types of roundabouts: "Turbo", "flower", "target" and "four-flyover" roundabout. Periodica Polytechnica Civil Engineering, 60(1), 51-60. 